\title{
Practical Implementation of Virtual Lean and Agile Manufacturing Systems - Application of a Generic Framework
}

\author{
A.K. Kochhar
}

Manufacturing Division

Department of Mechanical Engineering

University of Manchester Institute of Science and Technology (UMIST)

Manchester M60 1QD, U.K.

Tel: +44 (0) 1612003801

Fax: +44 (0) $1612008721 / 3803$

E-Mail:mcjmscc@fsl.me.umist.ac.uk

\begin{abstract}
Recent years have witnessed a high level of interest in the design and implementation of lean and agile manufacturing systems. Very often the development of such systems requires the creation of relationships with companies, with specialist capabilities, in different parts of the world. A virtual enterprise, which can be brought together to respond quickly to emerging market needs and achieve specific goals, is a strategic but relatively complex approach to the implementation of lean and agile manufacturing systems. This paper describes a framework around which the necessary decisions can be made.
\end{abstract}

Keywords

Lean, Agile, Virtual, Manufacturing, Framework 


\section{INTRODUCTION}

Recent years have witnessed a very high level of global competition in the manufacturing industries. There is no sign of any reduction in the level of competition. On the contrary, this competition can be expected to increase as the newly industrialised countries, with their relatively low labour costs, continue to gain an ever increasing share of world trade in manufactured goods. Simultaneously, the level of customer expectations is also increasing. Increasingly, in markets all over the world, the customer is king. Customers demand value for money, thereby requiring manufacturing companies to produce high quality products, in an ever increasing variety of configurations, at low cost and deliver them at short notice. There has been a shift from high volume, low mix manufacture, involving economies of scale, to low volume, high mix manufacture. This often involves many changeovers, special handling and customised products with costs similar to those for mass produced items. Very often the components and sub-assemblies used to assemble relatively complex products are manufactured in different parts of the world. The future of manufacturing lies in a high level of co-operation, involving work sharing between regions of the world. In such a scenario, a company, or group of companies, may assemble products, in different regions of the world, using a global supply chain. Automotive and aerospace industries are examples of such global enterprises.

Western companies are reacting to this mass production scenario in a variety of ways since they can no longer compete with low cost developing countries. In an attempt to maintain their share of the market, and regain a competitive edge, they have been restructuring their operations in a variety of ways. Manufacturing operations have been streamlined in order to minimise the extent of non-value adding activities. In other instances, complete layers of management have been removed. High level of automation is helping to improve the quality of products by reducing the need for unskilled workers. Techniques such as concurrent engineering are being used in order to reduce the time-to-market, and at the same time reduce overall costs by designing products for manufacture and/or assembly. Suppliers are often involved at the early stage of the design process. Multinational companies are setting up operations in different parts of the world. Other companies are responding to the challenges by sub-contracting some of their manufacturing operations, forming global alliances and strategic partnerships. While these steps have helped some manufacturing companies to regain a competitive edge, they do not really address many of the issues which are likely to affect the manufacturing companies during the twenty-first century. Very few of the manufacturing companies are truly world class and really lean, mean. and agile. 


\section{TWENTY-FIRST CENTURY MANUFACTURE}

There is an overwhelming consensus of opinion that the 21st century manufacture is likely to have the following characteristics.

1. Mass customisation of products with costs equal to or less than the costs of mass produced items.

2. Product manufacture in small lots.

3. Reconfigurable factories.

4. Readily available access to technology.

5. Supplying products anywhere in the world at short notice.

6. Manufacturing products where the market is.

7. Global market and supply chains.

8. Ready availability of information.

9. Ever increasing levels of customer expectations.

10. Rapid technological advances.

11. Intelligent and empowered workforce.

12. High level of emphasis on recycling and environmental issues.

13. Global shifting of job skills.

14. Flexibility and agility of operations.

15. High level of flexible automation.

16. Remote performance monitoring, diagnosis and control

17. Unmanned or very tightly manned operations.

18. Multi-media information environment for acquisition, processing, learning and transfer of information.

19. Learning organisations.

20. High level of team working in companies as well as between customers and suppliers.

21. Continuous evolution in response to customer demands.

It is clear that organisations will have to be highly responsive and use all of their own resources, as well as the resources of their partners, suppliers and potential suppliers in an intelligent and flexible manner to respond to global customers and survive in the market place. This will require the implementation of lean, agile and virtual manufacturing systems.

\section{IMPLEMENTING LEAN, AGILE AND VIRTUAL MANUFACTURING SYSTEMS}

In a world of constantly shifting paradigms, it is important to have unambiguous definitions of terms. 
Lean manufacture has been defined as a set of practices intended to remove all the waste from the manufacturing system (Noaker, 1994). Efforts made by advanced companies, in particular those in the automotive sector, have resulted in considerable progress in the achievement of lean manufacture. Other companies have also implemented practices such as just-in-time manufacture, supplier development, team working, removal of unnecessary layers of management, and continuous improvement. All of these help with the achievement of lean manufacture. However, lean manufacture does not mean it will lead to agility. The best examples of lean manufacture are to be found in the automotive sector, in particular Japanese companies which perfected lean manufacture in conditions of steadily growing export markets. As markets become unpredictable and unstable, lean manufacturing systems can have considerable difficulty in responding quickly to the changed circumstances. Close, long term customer-supplier relationships may mean that an organisation is locked in a relationship with a company which does not have the technology required to deal with changed conditions. In contrast, agile manufacturing involves the formation of short-term relationships between companies in order to respond to a particular set of market conditions, to the benefit of all the partners involved.

Agility is often confused with flexibility. An organisation can become flexible by reducing overheads, improving the skills of the employees thereby ensuring that they are multi-skilled and capable of performing a variety of tasks, team working and delayering. Short set up times, cellular manufacture, total productive maintenance etc have helped companies to reduce their lead times and become responsive to the market. However, as remarked earlier, flexibility does not lead to agility.

According to Goldman et al (1995), four main principles form the core of agile enterprises.

1. Providing customer value.

2. Responding to change.

3. High level of emphasis on human knowledge and skills

4. Formulation of virtual partnerships.

These agile organisations must be capable of responding to future changes by formulating partnerships with complementary organisations anywhere in the world and by harnessing the knowledge and skills of their employees in order to provide the best value for money for their customers.

It is generally accepted that as organisations increasingly focus on core competencies very few manufacturing companies have all the capabilities which will enable them to take timely advantage of the opportunities as they arise in the market. It is in this context that the Virtual Enterprise concept helps with the implementation of the agile manufacturing systems. 
Paul Kidd (1994) describes virtual organisations as a group of companies with different but complementary core competencies joined together to produce a certain range of products. So, where one company concentrates on design, another is in charge of the manufacture and the marketing is left in the hands of a third partner. These partners do not have to be geographically close as the information can be shared electronically. These partnerships can be disbanded once the goals that put them together in the first place have been achieved. According to Tom Peters (1991), managing these tasks is not an easy task. Organisations can make mistakes when joining these joint ventures if they are not careful. Cheeseborough and Teece (1996) suggest that organisations should not seek to become part of virtual enterprises just to follow the trend. The type of products made by the company and the level of innovation that these products require are aspects that should be taken into account.

While it is possible and relatively easy to share information about product specifications etc, the real problem lies in quickly building trust and exchange of strategic information in such virtual enterprises.

Thus, the creation of virtual, lean and agile manufacturing systems involves a number of complex tasks and careful consideration must be given to all the important parameters involved.

\section{DECISION FRAMEWORK}

Agility cannot be achieved overnight. Partners in a virtual enterprise will develop different levels of agility. Before formulating such partnerships, it is essential to assess the extent to which the goals and the current practices of an organisation match the characteristics of an agile manufacturing enterprise. A conceptual framework, shown in figure 1, has been developed to assess the current levels of agility of different enterprises.

\section{Market Environment}

Since markets are continually being subjected to unpredictable changes in demand patterns, agile manufacturers must be able to cope with changes. This part of the framework assesses the market environment in which the company operates.

\section{Manufacturing Strategy}

The manufacturing strategy adopted by the company enables it to satisfy the market environment. Since agility requires team working alongside collaboration with global partners, visionary strategies must be developed and all the company employees must be involved in the achievement of business goals. 


\section{Performance Measurement System}

The performance measurement system must complement the agility objective and the associated manufacturing strategy. Many companies, while attempting to be lean and agile, continue to use traditional performance measurements to assess the effectiveness of their operations.

\section{Concurrency}

Agile manufacture requires significant emphasis on establishing a smooth flow and sharing information across different departments, so that all the activities can be carried out concurrently.

\section{Suppliers}

An agile manufacturer cannot operate in isolation and must collaborate with suppliers to the benefit of both parties. Suppliers must be seen as close business partners in order to achieve certain well defined objectives.

\section{Lead Time}

For an organisation to be agile its lead times must be minimal. All non-value adding activities must be eliminated since they obviously slow down the process.

\section{Technology}

In agile manufacture, technology is a means of improving the knowledge and capabilities of the workforce. At the same time, technology must make it possible to respond quickly to demand changes and facilitate the reconfiguration of factories.

\section{Quality Performance}

Since agile manufacture involves customisation of products, traditional time may not be available to create perfect quality products. Hence rigorous disciplines and procedures must exist to provide the required high level of quality performance.

\section{Production Flexibility}

Production flexibility may involve the ability to produce many different types of products on the same line or changes in the production volumes. It also involves the flexibility of employees and the ability to quickly reconfigure manufacturing systems.

\section{Customer Responsiveness}

In an age of customer as king, a high level of responsiveness to customers, at every stage of the order processing, starting with the first contact until the product is delivered, is of utmost importance. 


\section{Education and Training}

In an agile manufacturing environment, the knowledge and the skills of the employees must be continually enhanced. Education and training programs, not necessarily limited to technical aspects, are very important. Involvement and empowerment will not be achieved if the employees are not trained to take up different roles in the company.

\section{Team Working}

Team working, across the whole organisation, is essential for responding quickly to changes in the market place.

The above framework only assesses the internal agility of an organisation. Many other parameters, not discussed in this paper, will have to be considered when formulating partnerships with other companies. These will relate to the organisation of the task, competitiveness of the partners, their cost structures, flexibility of the partners, information systems, integration mechanisms, communications mechanism and decision making mechanisms.

\section{APPLICATION OF THE FRAMEWORK}

The framework described in the previous section has been converted into a detailed questionnaire for practical applications. It has been used to assess the agility of a manufacturing company which has been formulating strategic and opportunistic partnerships throughout the world. It has experienced some problems in formulating effective partnerships. Face to face interviews were carried out to assess the strengths and weaknesses, as they relate to agility, and to recommend the necessary actions. Lack of space prevents a detailed discussion of the findings.

The major strengths of the company, as they relate to agility, were;

1. Ability to accurately predict the likely changes in the market place.

2. Detailed understanding of market requirements.

3. High level of innovation of products.

4. A clearly defined mission statement.

5. Visionary management.

6. Communication of information to all levels of the organisation.

7. Effective concurrency of activities.

8. Effective make versus buy decision making process.

9. High level of service from suppliers.

10. Cellular manufacturing systems used in part of the plant.

11. Investment in advanced technology and full awareness of technological advances which can facilitate agility.

12. Effective computer based manufacturing systems. 
13. Emphasis on product quality.

14. Multi-functional and multi-skilled workforce.

15. Modular product design.

16. Long serving and loyal workforce.

17. High level of emphasis on education and training including the development of personal skills.

18. Considerable emphasis on team working.

19. Ad-hoc teams formed to solve problems as they are encountered.

20. High level of management support for shop-floor activities.

The agility related weaknesses of the company are;

1. Lack of adequate priority for the customisation of products.

2. Use of traditional measures of performance.

3. Frequent delays in the analysis of problems.

4. Lack of effective integration of design and manufacturing activities.

5. Outdated criteria for selection of suppliers.

6. Time-consuming selection of suppliers.

7. Poor communication with suppliers.

8. Value adding time still a relatively small proportion of the total product lead time.

9. Relatively high levels of work-in-progress and queues.

10. Traditional quality control systems.

11. Significant scope for improvements in team working.

The application of the framework made it possible to assess the agility of the enterprise. It is clearly not as agile as it should be. Its management is aware of what it must do in order for it to become agile. It has implemented many changes in recent years that have made it far more agile than it previously was. However, a considerable amount of work needs to be done before it becomes fully agile. Perhaps the most important finding is that the company recognises the need for further change, as revealed by the results of the application of the framework. It is taking action to improve its working practices in the identified areas.

All manufacturing environments are becoming increasingly dynamic. The framework described here can be used to assess these changes by reusing it at regular intervals and determine whether any improvements have been made. Clearly many such improvements are centred around team working and the need for a cultural change. Such cultural change can be achieved only by a high level of management commitment, employee involvement, education and training. 


\section{CONCLUSION}

Lean, agile and virtual manufacture is perceived as the model of the world class manufacturing organisations in the twenty-first century. The actual achievement of lean and agile manufacturing systems involves a very considerable amount of effort on a number of different fronts. Very often, agile manufacture will involve the formation of virtual enterprises involving partnerships between companies with specialised capabilities. Considerable care needs to be exercised when formulating such partnerships. All parts of any virtual enterprise need to be agile since any bottleneck in any part of the enterprise will mean that the overall system is ineffective. The framework described in this paper can be used to assess the agility of individual enterprises.

\section{REFERENCES}

Cheeseborough, H.W. and Teece, D. (1996) When is Virtual Virtuous? Organising for Innovation, Harvard Business Review, Jan-Feb 1996, 65-73

Goldman, S. , Nagel, R. and Preiss, K. (1993) Agile Competitors and Virtual Organisations, Van Nostrand Reinhold, New York

Kidd, P. (1994) Agile Manufacturing: Forging New Frontiers, Addison Wesley

Noaker, P. (1994) The Search for Agile Manufacturing, Manufacturing Engineering, 13, 5, 40-43

Peters, T. (1991) Get Innovative or Get Dead (Part 1), IEEE Engineering Management Review, 19, 4.

\section{BIOGRAPHY}

Ashok Kochhar is the Lucas Professor of Manufacturing Systems Engineering at the University of Manchester Institute of Science and Technology ( UMIST ), Manchester, United Kingdom and Head of the Department of Mechanical Engineering. He was elected a Fellow of the Royal Academy of Engineering in 1997. His main research interests are the design, planning and control of manufacturing systems, benchmarking and performance measurement. Much of his research is carried out in active collaboration with industry. 